\title{
Screening the Methylation Status of DAPK Gene Using Plant Extracts in a Lung Cancer Cell Line
}

\author{
Kinshuk Seth ${ }^{1}$, Ayushi Singh ${ }^{1}$, Abhimanyu Kumar Jha ${ }^{1 *}$, Anand Swaroop Shukla ${ }^{2}$ and Anju Shrivastava ${ }^{2}$ \\ ${ }^{1}$ Department of Biotechnology, IMS Engineering College, India
}

${ }^{2}$ Department of Zoology, Delhi University, India

Submission: May 24, 2017; Published: July 26, 2017

*Corresponding author: Abhimanyu Kumar Jha, Department of Biotechnology, IMS Engineering College, Ghaziabad (U.P), India -201009, Email: abhimanyu2006@gmail.com

\begin{abstract}
Globally cancer is a disease which severely effects the human population. There is a constant demand for new therapies to treat and prevent this life-threatening disease. Scientific and research interest is drawing its attention towards naturally-derived compounds as they are considered to have less toxic side effects compared to current treatments such as chemotherapy. Cancer chemoprevention with natural phyto chemical compounds is an emerging strategy to prevent, impede, delay, or cure cancer. Plant extracts protect against toxic chemical-induced injury by increasing the body's levels of antioxidant molecules, such as glutathione, and enhancing the activity of antioxidant enzymes. These enzymes protect cellular organelles and membranes by fighting free radical damage caused by a lack of oxygen and other toxic agents. In the present study, A549 cancer cell line did not show promoter hyper methylation of DAPK gene. The unmethylation specific band was observed even after treatment with the three extracts selected for the present study. However, the intensity of these bands was found to vary with the treatments with the ethanolic extracts of Ocimum sanctum, Azadirachta indica and Withania somnifera.
\end{abstract}

Keywords: DAPK; A549; Plant extracts; Chemotherapy; Photochemical; Antioxidant

\section{Introduction}

Cancer is a disease which occurs when changes in a group of normal cells within the body lead to uncontrolled growth causing a lump called a tumor; this is true of all cancers except leukaemia (cancer of the blood). If left untreated, tumors can grow and spread into the surrounding normal tissue, or to other parts of the body via the bloodstream and lymphatic systems, and can affect the digestive, nervous and circulatory systems.

\section{Tumors (lumps) can be benign or malignant}

Benign tumors are not cancerous and rarely threaten life. They tend to grow quite slowly, do not spread to other parts of the body and are usually made up of cells quite similar to normal / healthy cells. They will only cause a problem if they grow very large, becoming uncomfortable or press on other organs - for example a brain tumor inside the skull. Malignant tumors are faster growing than benign tumors and have the ability to spread and destroy neighboring tissue. Cells of malignant tumors can break off from the main (primary) tumor and spread to other parts of the body through a process known as metastasis. Upon invading healthy tissue at the new site, they continue to divide and grow. These secondary sites are known as metastases and the condition is referred to as metastatic cancer.

Due to cytotoxic effects of most of the chemical compounds, the focus is biased toward natural products for the epigenetic reversal. Phytochemicals derived from fruits and vegetables, referred to as chemo preventive agents, include genistein, diallyl sulphide, S-allyl cysteine, allicin, lycopene, curcumin, 6-gingerol, ursolic acid, silymarin, anethol, catechins and engenol [1]. This chemo preventive agent has potential to be used as adjuncts to current cancer therapies [1]. Epigallocatechin3-gallate (EGCG) has been shown to cause demethylation of the CpG islands in the promoters and reactivation of methylation silenced genes such as p16INK4a, retinoic acid receptor s, 06-methylguanine methyl transferase, human mutL homologue 1 , and glutathione S-transferase- $\pi$ in human oesophageal, colon, prostate, and mammary cancer cell lines [2]. The demethylating activity can be enhanced by the presence of histone deacetylase inhibitors or by longer-term treatment [3]. Soy-derived genistein and lycopene from tomato have been shown to alter gene expression in ways that can either promote or potentially inhibit the 
carcinogenic processes in breast cancer cell lines. Both genistein and lycopene, at very low, dietarily relevant concentrations can potentially mitigate tumorigenic processes via promoter methylation modulation of gene expression [4]. Not much data is available on reversal of promoter hypermethylation by natural compounds in cervical cancer cell lines.

Epigenetic mechanism is a significant event in the development and progression of cancer. It refers to "the heritable changes in gene expression that do not result from alterations in gene nucleotide sequence". DNA methylation act to regulate gene expression in normal mammalian development along with that promoter hyper methylation part in cancer through transcriptional silencing of critical growth related regulators such as tumor suppressor genes. Local chromatin structure can be affected by histone deacetylation and chromatin binding protein. The effect of these methylation inhibitors is providing new and effective options for the patients suffering from leukemias and other disease related to it.

DNA methylation, primarily at the C5 position of cytosine, affects gene expression in many biological methylation processes such as differentiation; genomic imprinting, DNA mutation, and DNA repair. DNA hypermethylation, occurs usually at promoter $\mathrm{CpG}$ islands, is one of the major epigenetic mechanism in silencing the expression of genes [5]. The promoter hypermethylation as well as global hypomethylation have been found to play an important role in carcinogenesis. Epigenetic silencing of tumor suppressor genes is emerging as a well-established oncogenic process and reactivation of tumor suppressor genes that have been silenced by promoter methylation is a very attractive molecular target for cancer therapy [6]. There are several demethylating agents currently being evaluated in preclinical and clinical studies. 5-aza-cytidine and 5-aza-2-deoxycytidine are the most studied and were developed over 30 years ago as classical cytotoxic agents, but were subsequently discovered to be effective DNA methylation inhibitors. Zebularine is a new oral cytidine that has been shown to cause demethylation and reactivation of the silenced and hyper methylated p16 gene [7]. Some other drugs such as procainamide and hydralazine are also in different stages of trial [6].

\section{A549 cell line}

A549 cells were first developed in 1972 through the removal and culturing of cancerous lung tissue in the explant tumor of a 58-year-old Caucasian male [8]. The ATCC standardly conduct characterization of genotype and karyotype of the parent cells prior to distribution. A549 is a hypo triploid human cell line with a modal chromosome number of 66 , occurring in $24 \%$ of cells. Cells containing 64 (22\%), 65, and 67 chromosomes occur at relatively high frequencies but ATCC have reported the rate of cells with higher ploidies is low $(0.4 \%)$. There were six markers present in single copies in all cells, including del (11) (q21), del (2) (q11), M4 and M5 [9]. Most cells were found to have two X and two Y chromosomes, although one or both Y chromosomes were lost in $40 \%$ of 50 cells analyzed. Chromosomes N2 and N6 had single copies per cell; and N12 and N17 usually had 4 copies.

\section{Materials and Methods}

\section{Collection of cell line}

The Lung cancer cell line A549, was procured from the National Centre for Cell Sciences (Pune, India).

\section{Plant extract preparation}

Leaves of the Withania somnifera, Azadirachta indica and Ocimum sanctum was shade dried and powdered. Powdered leaves were taken in $2 \mathrm{ml}$ centrifuge tube $(10 \mathrm{mg}$ ) and $1 \mathrm{ml}$ absolute alcohol added. Now the ethanol extract was dried in incubator. Dried powder from ethanol was dissolved in DMSO.

\section{Cell culturing}

$5 \times 10^{3}$ cells/well seeded in 6 well culture as per the need of doses and limit points. The incubated cells were kept in 200 $\mu \mathrm{l} /$ $\mathrm{ml}$ DMEM for $2 \mathrm{hr} 30$ minutes for adherence. Treat all the wells beside control and incubate for respective times.

\section{Crystal violet test}

$25 \mu$ l of Crystal Violet was added to all the wells containing the treatment. $10 \mu \mathrm{l}$ of $1 \%$ SDS was added to each of the well to solubilize the stain. The wavelength was set to $540 \mathrm{~nm}$ and the readings were taken. These readings were noted down and graphs were formulated. The graph made from the readings give us the $\mathrm{IC}_{50}$ values of the photochemical. Based on these values, efficient doses of treatment can be formulated.

\section{DNA extraction}

Cells obtained from blood samples were lysed in digestion buffer (10mM Tris-HCl, pH 8.0, 10mM EDTA, $150 \mathrm{mM} \mathrm{NaCl}$ and $2 \% \mathrm{SDS})$ containing proteinase $\mathrm{K}(0.2 \mathrm{mg} / \mathrm{ml})$. DNA was then purified using the standard phenol-chloroform extraction and ethanol precipitation.

\section{Sodium Bisulphite modification}

Bisulphite modification of cell line was done $(0.3 \mathrm{M} \mathrm{NaOH}$, 10mM Hydroquinone, $40.5 \%$ Sodium Bisulphite, TE Buffer, Mineral oil, 1\% Agarose) and the bands was viewed by running gel electrophoresis.

\section{Methylation-specific PCR (MS-PCR)}

Table 1: Sequence of primers.

\begin{tabular}{|c|c|c|c|}
\hline Primers & Sequence & $\begin{array}{c}\text { Volume } \\
\mathbf{1 0 0 \mu \mathbf { M }}\end{array}$ & $\begin{array}{c}\mathbf{T m} \\
\left({ }^{\circ} \mathbf{C}\right)\end{array}$ \\
\hline $\begin{array}{c}\text { DAPK Methylated } \\
\text { Forward }\end{array}$ & $\begin{array}{c}\text { GGATAGTCGGAT } \\
\text { CGAGTTAACGT }\end{array}$ & 261.4 & 57.0 \\
\hline $\begin{array}{c}\text { DAPK Methylated } \\
\text { Reverse }\end{array}$ & CCCTCCAAACGCCGA & 309.0 & 51.0 \\
\hline $\begin{array}{c}\text { DAPK Unmethylated } \\
\text { Forward }\end{array}$ & $\begin{array}{c}\text { GGAGGATAGTTGGAT } \\
\text { TGAGTTAATGTT }\end{array}$ & 162.8 & 55.0 \\
\hline $\begin{array}{c}\text { DAPK Unmethylated } \\
\text { Reverse }\end{array}$ & $\begin{array}{c}\text { CAAATCCCTCC } \\
\text { CAAACACCAA }\end{array}$ & 217.2 & 52.0 \\
\hline
\end{tabular}


DNA isolated from the cell lines was modified with sodium bisulphite and MS-PCR was carried out using specific primers for methylation and unmethylation for the $A 549$ and DAPK genes (Table 1 ). The amplified products were run on a $2 \%$ agarose gel.

\section{Results}

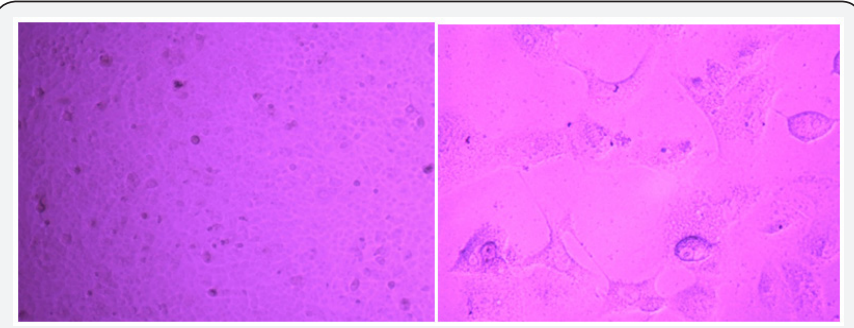

Figure 1: Morphological Changes observed in A549 cell line after treatment with Azadirachta indica ethanolic extract. ethanolic extract.

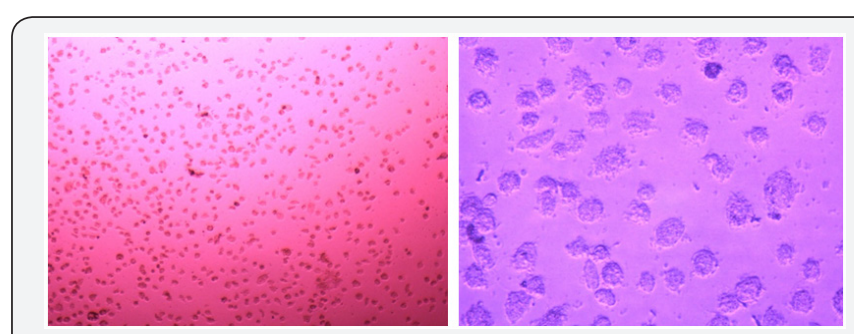

Figure 2: Morphological Changes observed in A549 cell line after treatment with Withania somnifera ethanolic extract.

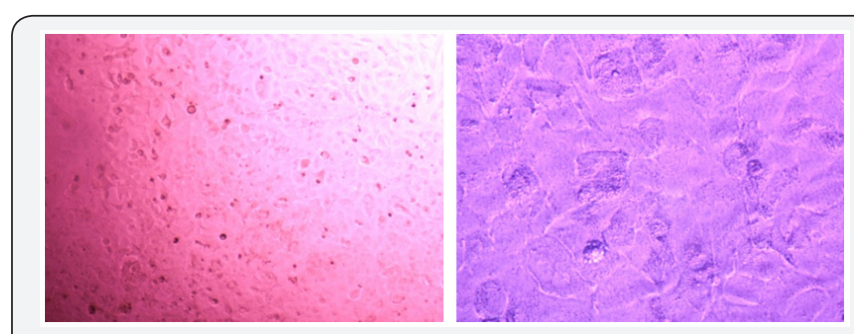

Figure 3: Morphological Changes observed in A549 cell line after treatment with Azadirachta indica ethanolic extract.

Crystal violet assay reveals the apoptosis taken place in A549 cell line in different treatment of drugs given to the cultured cell line. Since, methylation specific band was not observed in A549 cell, but the unmethylation specific band was clearly observed in the A549 cells. We tried to check the effect of the treatment of the three extracts i.e. Azadirachta indica (Figure 1), Withania somnifera (Figure 2) and Ocimum sanctum (Figure 3) at 50 $\mu \mathrm{g} /$ $\mathrm{ml}$ concentration but still, there the unmethylation specific band was present even after the treatment, with these extracts.

\section{Discussion}

In last few years there has been many research, focusing on epigenetic changes resulting in neoplasia and their possible reversal using natural compounds. It has been concluded that epigenetic changes such as DNA methylation can be reversed. The two forms of heritable information, namely genetic and epigenetic, are collectively denoted as dual inheritance. Members of the APOBEC/AID family of cytosine deaminases may concurrently influence genetic and epigenetic inheritance using similar molecular mechanisms, and may be a point of crosstalk between these conceptually compartmentalized processes [10]. Fluoroquinolone antibiotics induce epigenetic changes in mammalian cells through iron chelation. This leads to epigenetic effects through inhibition of $\alpha$-ketoglutarate-dependent dioxygenases that require iron as a co-factor [11].

Various pharmacological agents are applied for the production of induced pluripotent stem cells (iPSC) or maintain the embryonic stem cell (ESC) phenotypic via epigenetic approach. Adult stem cells like bone marrow stem cells have also shown a potential to differentiate into cardiac competent cells when treated with G9a histone methyltransferase inhibitor BIX0129 [12]. With the recent study on phytochemicals cause the reversal of hypermethylation and reactivation of tumor suppressor gene. Jha et al. [13] showed the reversal of hypermethylation and reactivation of $R A R \beta 2$ gene in SiHa cell line by the Withania somnifera. They had already been shown that curcumin and genistein cause reversal of hypermethylation and reactivation of RAR $\beta 2$ gene [14].

Reversal of the methylated DNA of cancer cell lines, can also be shown by Several Dietary Polyphenols [3]. When the A549 cells were treated with the Ocimum sanctum, Withania somnifera and Azadirachta indica extracts, the apoptosis was observed in cells after $24 \mathrm{~h}, 48 \mathrm{~h}, 72 \mathrm{~h}$ and 6 days treatment, and increase in apoptosis was observed with increase in the concentration of the extracts as well as the time intervals i.e. $72 \mathrm{~h}$ and 6 days. The DNA was isolated from the treated and untreated cells after treatment with plant extracts for different intervals. This was followed by sodium bisulphite modification. After carrying out MSP, it was observed that methylation specific band was not observed in A549 cells, but the unmethylation specific band was clearly observed in A549 cells.

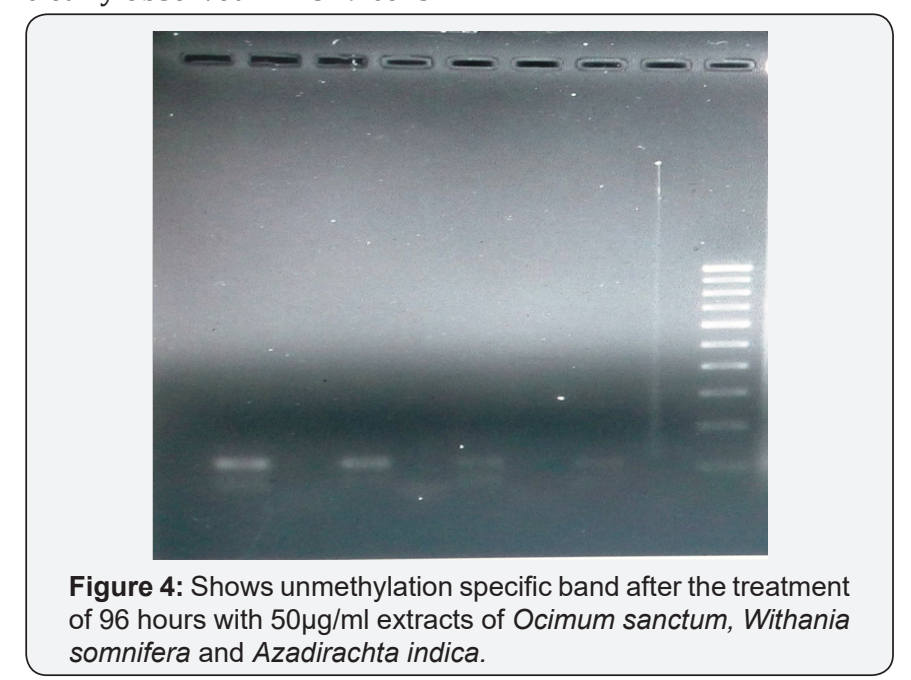

In the present study, we tried to calculate the effect of Ocimum sanctum, Azadirachta indica and Withania somnifera extracts $(50 \mu \mathrm{g} / \mathrm{ml})$ but still, the unmethylation specific band was observed even after treatment with these extracts. However, the intensity of these bands was found to vary with these (Ocimum 
sanctum, Azadirachta indica and Withania somnifera) ethanolic extract treatments. Hence, it can be concluded that A549 cells, do not show hypermethylation for promoter region of DAPK gene. The intensity of the UMSB (Unmethylation specific band) was found to decrease severely after the treatment with the Withania somnifera and Azadirachta indica extracts (Figure 4).

\section{References}

1. Dorai T, Aggarwal B (2004) Role of chemo preventive agents in cancer therapy. Cancer Lett 215(2): 129-140.

2. Fang MZ, Wang Y, Ai N, Hou Z, Sun Y, et al. (2003) Tea polyphenol (-)-epigallocatechin- 3-gallate inhibits DNA methyltransferase and reactivates methylation silenced genes in cancer cell lines. Cancer Res 63(22): 7563-7570.

3. Fang M, Chen D, Yang CS (2007) Dietary polyphenols may affect DNA methylation. J Nutr 137(1 Suppl): 223S-228S.

4. King-Batoon A, Leszczynska JM, Klein CB (2008) Modulation of gene methylation by genistein or lycopene in breast cancer cells. Environ Mol Mutagen 49: 36-45.

5. Roche (1996) Over expression of genes have in prostrate and breast cancer.

6. Gonzalez AD, Lizano M, Candelaria M, Cetina ML, Arce C, et al. (2005) Epigenetics of cervical cancer. An overview and therapeutic perspectives. Mol Cancer 4: 38.

7. Angeles E, Vázquez-Valadez, VH, Vázquez-Valadez O, VelázquezSánchez AM, Ramírez A, et al. (2005) Computational studies of 1-hydrazinophtalazine (hydralazine) as antineoplastic agent. Docking studies on methyltransferase. Lett Drug Des Discov 2(4): 282-286.

8. Giard DJ, Aaronson SA, Todaro GJ, Arnstein P, Kersey JH, et al. (1973) In vitro cultivation of human tumors: establishment of cell lines derived from a series of solid tumors. J Natl Cancer Inst 51(5): 1417-1423.

9. Marostica LL, de Barros AL, Silva JO, Lopes SC, Salgado BS, et al. (2016) Oliveira, Feasibility study with $99 \mathrm{mTc}$-HYNIC- $\beta$ Ala-Bombesin as an agent to early visualization of lung tumour cells in nude mice, Nuclear Medicine Communications 37(4): 372.

10. Chahwan R, Wontakal SN, Roa S (2010) Crosstalk between genetic and epigenetic information through cytosine deamination. Trends Genet 26(10): 443.

11. Badal S, Her YF, Maher LJ (2015) Nonantibiotic Effects of Fluoroquinolones in Mammalian Cells, J Biol Chem 290(36): 22872297.

12. Mezentseva NV, Yang J, Kaur K, Iaffaldano G, Rémond MC, et al. (2012) The histone methyltransferase inhibitor BIX01294 enhances the cardiac potential of bone marrow cells. Stem Cells Dev 22(4): 654-667.

13. Jha AK, Nikbakht M, Parashar G, Shrivastava A, Capalash N, et al. (2010) Reversal of hypermethylation and reactivation of the RAR62 gene by natural compounds in cervical cancer cell lines. Folia Biol (Praha) 56: 195-200.

14. Jha AK, Nikbakht M, Capalash N, Kaur J (2014) Demethylation of RARB2 gene promoter by Withania somnifera in HeLa cell line. European Journal of Medicinal Plants 4(5): 503510.

\section{Your next submission with Juniper Publishers will reach you the below assets}

- Quality Editorial service

- Swift Peer Review

- Reprints availability

- E-prints Service

- Manuscript Podcast for convenient understanding

- Global attainment for your research

- Manuscript accessibility in different formats

( Pdf, E-pub, Full Text, Audio)

- Unceasing customer service

Track the below URL for one-step submission https://juniperpublishers.com/online-submission.php 